\title{
El deporte, los pueblos originarios y las perspectivas ideológicas: entre el racialismo de los Juegos Olímpicos de Saint Louis (1904) y la reafirmación étnica de los Juegos Mundiales de los Pueblos Indígenas
} (2015)

Sport, indigenous peoples and ideological perspectives: between the racialism of the Saint Louis Olympics (1904) and the ethnic reaffirmation of the World Games of Indigenous Peoples (2015)

\author{
Aurelio Arnoux Narvaja \\ Orcid: https://orcid.org/0000-0001-7585-5271/ \\ Instituto de Altos Estudios Sociales, Universidad de San Martin (IDAES- \\ UNSAM), Buenos Aires, Argentina, abnarvaja@gmail.com
}

Received on 10/05/2020 - Approved on 27/05/2020

\section{Resumen:}

En este trabajo se pretende indagar sobre las representaciones e imaginarios en torno a los pueblos indígenas a partir del análisis de dos eventos culturales distintos: los "juegos antropológicos" de Saint-Louis (1904) y los Juegos Mundiales de los Pueblos Indígenas en Brasil (2015). Se utilizará la perspectiva de análisis comparativo cualitativo (Ariza y Gandini, 2015) enfatizando en los discursos sociales y políticos que evocan y en las dimensiones simbólicas que expresan, atendiendo, entre otros, a la representación del cuerpo. Mientras que en el primer caso hay un claro propósito de etiquetamiento, de clasificación, de occidentalización, en el segundo se vislumbra resistencia, emancipación, apropiación.

Palabras Claves: Juegos Antropológicos. Juegos Mundiales Indígenas. Representaciones sociales. Occidentalización. Resistencia. Cuerpos.

\section{Abstract}

This work aims to investigate the representations and imagery around indigenous peoples from the analysis of two different cultural events: the "anthropological games" of Saint-Louis (1904) and the World Games of Indigenous Peoples in Brazil (2015). The perspective of qualitative comparative 
analysis (Ariza and Gandini, 2015) will be used, emphasizing the social and political discourses they evoke and the symbolic dimensions they express, taking into account, among others, the representation of the body. While in the first case there is a clear purpose of labeling, classification, westernization, in the second there is a glimpse of resistance, emancipation, appropriation.

Key Words: Anthropological Games. Indigenous World Games. Social representations. Westernization. Resistance. Bodies.

\section{Introducción}

El deporte ha sido a lo largo de la historia una práctica humana que ha trascendido sociedades y tiempos, promoviendo en muchos casos encuentros culturales, como fueron los Juegos Olímpicos tanto antiguos como modernos que, para algunos, favorecían la consolidación de un sentido de hermandad internacional (Cousineau, 2008). Si bien en su esencia ha primado el espíritu solidario, democrático e inclusivo, en algunas oportunidades ha sido utilizado como fértil escenario de experiencias racialistas ${ }^{1}$ exacerbando las diferencias no sólo desde el punto de vista discursivo sino también desde las representaciones construidas en torno a los cuerpos. Esto fue lo que ocurrió en la exposición de Saint Louis en 1904 en dónde se realizaron, próximos a los Juegos Olímpicos, las "jornadas antropológicas", evento que trataba de exhibir la competencia entre los "pueblos salvajes". Más de un siglo después de este polémico experimento, en la ciudad de Palmas, al norte de Brasil, se organizaron los primeros Juegos Mundiales de los Pueblos Indígenas (experiencia que se enmarca dentro de eventos culturales homónimos que tienen una larga tradición desde fines de la década de 1970 (Ruiz Vicente y Hernández Vázquez, 2016)), en los que se intentó celebrar la unión de grupos diferentes más allá de las competencias atléticas. En uno y otro (las "jornadas antropológicas" y los Juegos Mundiales del 2015) los pueblos originarios fueron los protagonistas excluyentes pero los sentidos sociales que se construyeron fueron marcadamente diferentes.

En este trabajo nos proponemos indagar en los imaginarios y representaciones que se construyeron en torno a estos dos eventos, considerando el contexto, los actores, las pruebas realizadas, enfatizando en la expresión corporal y sus significaciones. Esquemáticamente, en una primera parte, haremos referencia a los "juegos antropológicos" celebrados en Saint Louis en 1904 analizando las imágenes peyorativas que se intentaron imponer; en una segunda instancia haremos lo propio con los Juegos Mundiales de los Pueblos Indígenas de 2015 interpretando los mensajes que los organizadores intentaron transmitir, particularmente de revalorización cultural; y por último realizaremos un abordaje contrastivo tomando como referencia diversas dimensiones susceptibles de ser comparadas.

Utilizaremos distintas fuentes primarias (recortes periodísticos, memorias oficiales, imágenes, crónicas, entre otras) que serán interrogadas con el auxilio de disciplinas próximas. Por un lado, haremos intervenir la Historia (en particular la Historia Social) y su perspectiva sobre el universo social de los sectores subalternos, en este caso los indígenas. En este sentido, y como 
anunciamos, recuperaremos algunas fotografías, recurso revelador "para acceder no ya directamente al mundo social, sino más bien a las visiones de ese mundo propias de una época" (Burke, 2005: p. 239). Por otro lado, apelaremos a la Antropología y su perspectiva de análisis, necesaria para desgranar los sentidos culturales a partir, entre otros, de las discursividades sociales.

\section{Saint Louis, Missouri (1904): las "jornadas antropológicas” en el marco de la exposición universal y los Juegos Olímpicos}

\section{Luisiana, la Exposición Internacional y los Juegos Olímpicos}

Desde mediados del siglo XIX, en correspondencia con el avance del capitalismo en los principales Estados occidentales, se comenzaron a organizar grandes exposiciones que atraían a numerosos visitantes de las más diversas procedencias (Hobwsbawn, 2010). El principal objetivo era hacer visibles los adelantos tecnológicos propios de la civilización y demostrar, en definitiva, cómo se estaba conformando un mundo divido entre países centrales y periféricos. Tal fue el éxito de estos eventos que aquella celebrada en París en 1900 tuvo como novedad el desarrollo en paralelo de los segundos Juegos Olímpicos modernos incorporando, así, una práctica cultural que mostrara el peso de la tradición greco-latina (en la Europa de esa época y en su área de influencia próxima) y las condiciones atléticas de los que se presentaban.

Estados Unidos formaba parte de estas "naciones privilegiadas", por lo que decide organizar en 1904, en la ciudad de Saint Louis, un evento internacional, en conmemoración del centenario de la adquisición de Luisiana. Esta exhibición tuvo un peso ideológico más fuerte que otras que ya venían teniendo lugar en los Estados Unidos como la Exposición Universal de Chicago (1893) y la de Búfalo (1901). La elección del lugar fue significativa. Recordemos que la compra de este extenso territorio a Francia en 1803 permitió, por un lado, la expansión hacia el oeste de las trece colonias que formalmente se habían independizado de Inglaterra en 1776 y, por otro, sedimentar en la consciencia colectiva un sentido de superioridad ligado al avance de la "raza blanca" (que hablaba inglés y era protestante), que se iba constituyendo como núcleo central de la nación estadounidense.

La muestra que cubría una extensión de 636 hectáreas, reflejo de lo opulento del proyecto, le asignaba un lugar preponderante a los avances urbanísticos, científicos y tecnológicos (por ejemplo, la electricidad, el automóvil - las nuevas formas de comunicación como el telégrafo sin hilo), destacándose, a su vez, la zona destinada a los pabellones extranjeros. Entre las aproximadamente cincuenta naciones expositoras resaltaban la alemana, la japonesa, la francesa y la española. La República Argentina, a pesar del magro presupuesto que le fue asignado (que se observa en los insistentes pedidos al Congreso Nacional de una mayor erogación presupuestaria ${ }^{2}$ ) y las diferencias entre las autoridades en torno a la imagen que se buscaba instalar ${ }^{3}$, tuvo una 
muy buena recepción por parte del público y de los jurados (Penhos, 2009), en particular con las obras de arte (como la famosa pintura de Ernesto de la Cárcova Sin pan y sin trabajo), los productos alimenticios (bizcochos Canale o galletitas Bagley, por ejemplo) o la colección de piezas arqueológicas halladas en su territorio.

Ahora bien, a la par de todas estas muestras de civismo o civilización se expusieron en forma completamente estereotipada grupos étnicos reducidos a piezas de museo. La exposición se empezó a poblar, así, con estas minorías provenientes de las partes más remotas del planeta que, a pesar de la diversidad cultural, tenían el común infortunio de ser vistos como subalternos. No es de extrañar, entonces, que a diferencia del resto de las delegaciones invitadas (y para enfatizar la dicotomía salvaje/civilización) cumplieran su estadía tal como lo expresa la revista Caras y Caretas (18 de febrero de 1905) en:

chozas, carpas, guaridas y otras clases de habitáculos que han servido de albergue a los indios que concurrieron a la Exposición de San Luis desde todas partes del mundo. No fue poco el trabajo que dio la construcción de tales mansiones; quienes, como los moros las deseaban en la copa de los árboles; quienes como los indios cocopas, las querían a la orilla del agua.

Imagen 1: Chozas de los indígenas

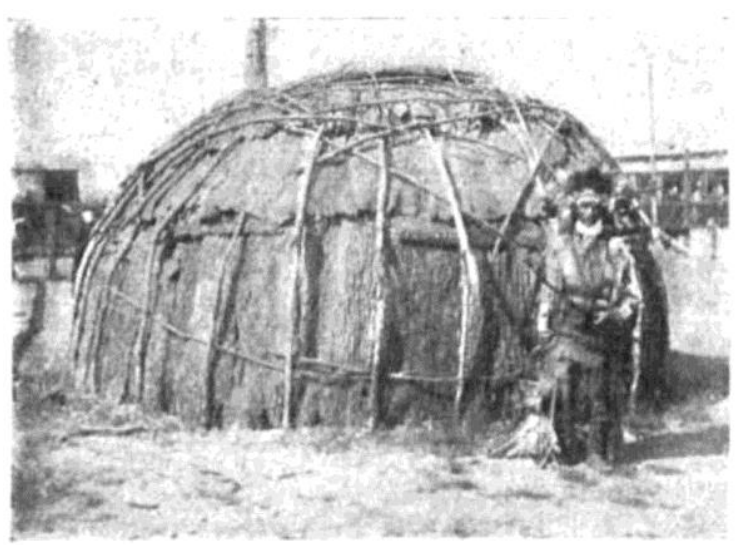

Choza kickpoo, construida con cortezas de olmo

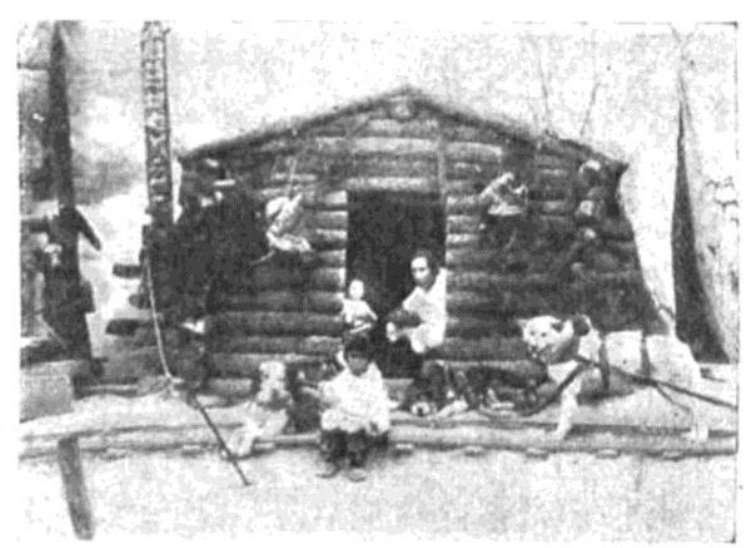

Cataña de esquimales

Fuente: Caras y Caretas (18 de febrero de 1905).

Como se desprende de esta referencia ( $y$ en consonancia con expresiones burlescas como atribuirle a las "chozas" la característica de "mansiones") las imágenes tienen un claro objetivo cosificador en dónde la familia, como se ve en la segunda imagen, se encuentra a la misma altura y posa igual que el animal con la diferencia de que este último se encuentra amordazado y los indígenas "sueltos" como infiriendo cierta docilidad; son "salvajes" pero han perdido su animalidad, la civilización los ha adiestrado. 
Además de grupos representativos de Estados Unidos, Japón, Filipinas - el continente africano fueron enviados ocho integrantes Tehuelches, "ejemplares escogidos en el territorio de Santa Cruz por el señor Vicente Cané, quién ha puesto especial cuidado en que sean los más vigorosos y corpulentos de esa raza que tiene fama de ser una de las fuertes" (Caras y Caretas, 26 de marzo de 1904). Etiquetados de acuerdo a la clasificación utilizada como "Patagones del Sur", eran los únicos representantes de América del Sur. De esta manera se reafirmaba el imaginario de la homogeneización que venía desde tiempos de la colonia y que, intencionalmente, ocultaba la verdadera diversidad.

En el marco de estos festejos se decidió, al igual que en París cuatro años antes, desarrollar los Juegos Olímpicos, tal vez para terminar de "convencer al público americano de que el deporte servía a los intereses del progreso y a la revitalización nacional" (Delsahut, 2012, p.2). En un principio, el Comité Olímpico Internacional, había propuesto la ciudad de Chicago, ícono del triunfo del desarrollo industrial. No obstante, y a pesar de la insistencia de Pierre de Coubertin ${ }^{4}$, no se pudo modificar el escenario, lo que implicó, en parte, que fueran muy pocos los atletas europeos presentes, opacando así la competencia. Esta situación desencadenó el enojo de los organizadores que no ahorraron calificativos despectivos, particularmente hacia Francia e Inglaterra que, en clara señal de hostilidad, no enviaron ningún competidor (Lucas, 1904).

Si bien hasta ahí las expresiones en torno a las cadenas de oposiciones (y equivalencias) moderno /hegemónico/civilizado y tradicional/subalterno/salvaje (García Canclini, 2001) habían sido más que evidentes, las autoridades decidieron acentuar estas clasificaciones organizando, como señalamos, como atractivo previo a los Juegos Olímpicos, unas jornadas conocidas como The anthropological athletic meet con los "mejores" exponentes indígenas que habían formado parte de la exposición.

\section{Las "jornadas antropológicas"}

Uno de los impulsores de este experimento fue William John McGee, primer presidente de la American Anthropological Association, prestigiosa institución fundada en 1902 que surgió para coordinar las decisiones políticoculturales y agrupar a los más reconocidos antropólogos (entre otros Franz Boas, para muchos el padre de la Antropología Norteamericana y uno de los más fervientes opositores al racismo), hasta entonces dispersos en muchas entidades. En ese contexto el paradigma dominante era "una suerte de mezcla del evolucionismo de Spencer y Morgan [por lo que McGee] se hizo repetidas veces culpable de reconstrucciones ingenuas, repletas de jingoístas exaltaciones spencerianas del éxito evolucionista de los Estados Unidos" (Harris, 1985: 221). Este evento contribuía, sin lugar a dudas, a reafirmar estos postulados. John Sullivan, otro de los promotores (y jefe del departamento de cultura física y de los Juegos Olímpicos) consideraba, a su vez, que estas experiencias podían colaborar para poner a prueba ciertos preconceptos ligados a la supuesta agilidad natural de los "salvajes" para las pruebas atléticas (Besnier, Brownell y Carter, 2018). 
Finalmente, las jornadas se llevaron a cabo los días 12 y 13 de agosto de 1904. Entre los pueblos indígenas seleccionados se encontraban, además de los Tehuelches, los Crow y Sioux de Estados Unidos, los Sirios de Beyrouth, los Pigmeos de Africa, los Igorots, los moros de Filipinas, los Ainu de Japón, los Cocopa de México o los Negritos de Filipinas. Recordemos, al respecto, que gran parte de estas categorizaciones (algunas hasta deformaciones de los nombres originales) han sido impuestas por occidente en el proceso de expansión.

En el primer día se desarrollaron pruebas olímpicas a las que los improvisados atletas evidentemente no estaban habituados y posiblemente (lo podemos inferir por la situación, aunque no contemos con fuentes que registren esas voces) ni siquiera tendían verdadero interés en realizarlas. El criterio de elección de las competencias estaba determinado por su adecuación al análisis antropométrico de las capacidades físicas y para comprobar, como señalamos, una idea anclada en el sentido común de la época según la cual "el salvaje medio es ligero de pies, fuerte de extremidades, preciso con el arco y la flecha y experto en la piedra debido a su peculiar estilo de vida" (Sullivan, 1905). El ganador de la carrera de 100 yardas fue George Mentz, como señala el cronista "un indio americanizado" con una performance "muy pobre" y fácilmente superable por cualquier "atleta universitario". Esta referencia no es menor si pensamos que desde el último tercio del siglo XIX existía un acalorado debate en Estados Unidos en torno al del deporte universitario: si se trataba de algo higiénico y pedagógico o si colaboraba en el paso de lo lúdico a lo laboral (Park, 2019). En cualquiera de los casos, inferimos que la crónica consideraba al "atleta universitario" como alguien que naturalmente estaba transitando su recorrido formativo, de ahí que tuviera una performance modesta pero superior que la de cualquier indígena que, no obstante, podría mejorar de acuerdo a los entrenamientos pautados o institucionalizados. Siguiendo el relato tal vez el caso más decepcionante haya sido el tiempo insumido por Lamba, un pigmeo africano, del cual se esperaba un desempeño mucho mejor dado su supuesto acostumbramiento a "una vida al aire libre, cazando, corriendo, nadando (...) vida propia de un atleta natural". Algo similar ocurrió con el lanzamiento de peso (o "Shot Puttin") de la cual se suponía que los Patagones, por su tamaño corporal y anatomía musculosa sobresaldrían. En síntesis, se acentuaba, sin eufemismos, esta falsa dicotomía entre naturaleza ("indios") y cultura ("atletas") estando los primeros evidentemente en una etapa incipiente de la evolución.

La siguiente jornada fue dedicada íntegramente a la demostración de destrezas de los participantes a partir de lo inferido por los organizadores como juegos "autóctonos". El tiro al blanco con arco fue una de las pruebas más esperadas. Independientemente de los resultados (que para Sullivan fueron, al igual que el día anterior, completamente desalentadores) lo que es interesante analizar es la imagen que acompaña el cuerpo del documento. En la misma se pueden decodificar algunos elementos propios de la percepción que se intentaba imponer. Por un lado, la cuasi total desnudez de los dos principales protagonistas, completamente diferente al fiscalizador vestido con traje y sombrero. Esta exhibición del "cuerpo desnudo", sin pudor, sin vergüenza, ausente de normas de comportamiento social contrastaba con el cuerpo vestido, civilizado y normalizado. A su vez, la edad del participante (un niño 
llamado Shake Cocopa) muestra, por un lado, la indiferencia a los aspectos etarios cuando se trata de indígenas y, por otro, enfatizar en la teoría de la recapitulación según la cual "los salvajes" habían "quedado empantanados en una etapa primitiva del desarrollo humano" (Gould, 2013, p.11) asociados a la infancia occidental (como si fueran "niños blancos"). Otra sutil pero no menor diferencia se desprende del lugar de las pruebas, presentado como escenario "natural", opuesta a la majestuosidad de la tribuna y las instalaciones construidas para los Juegos Olímpicos de ese mismo año.

Imagen 2: Tiro al arco o "Archery Shooting"7

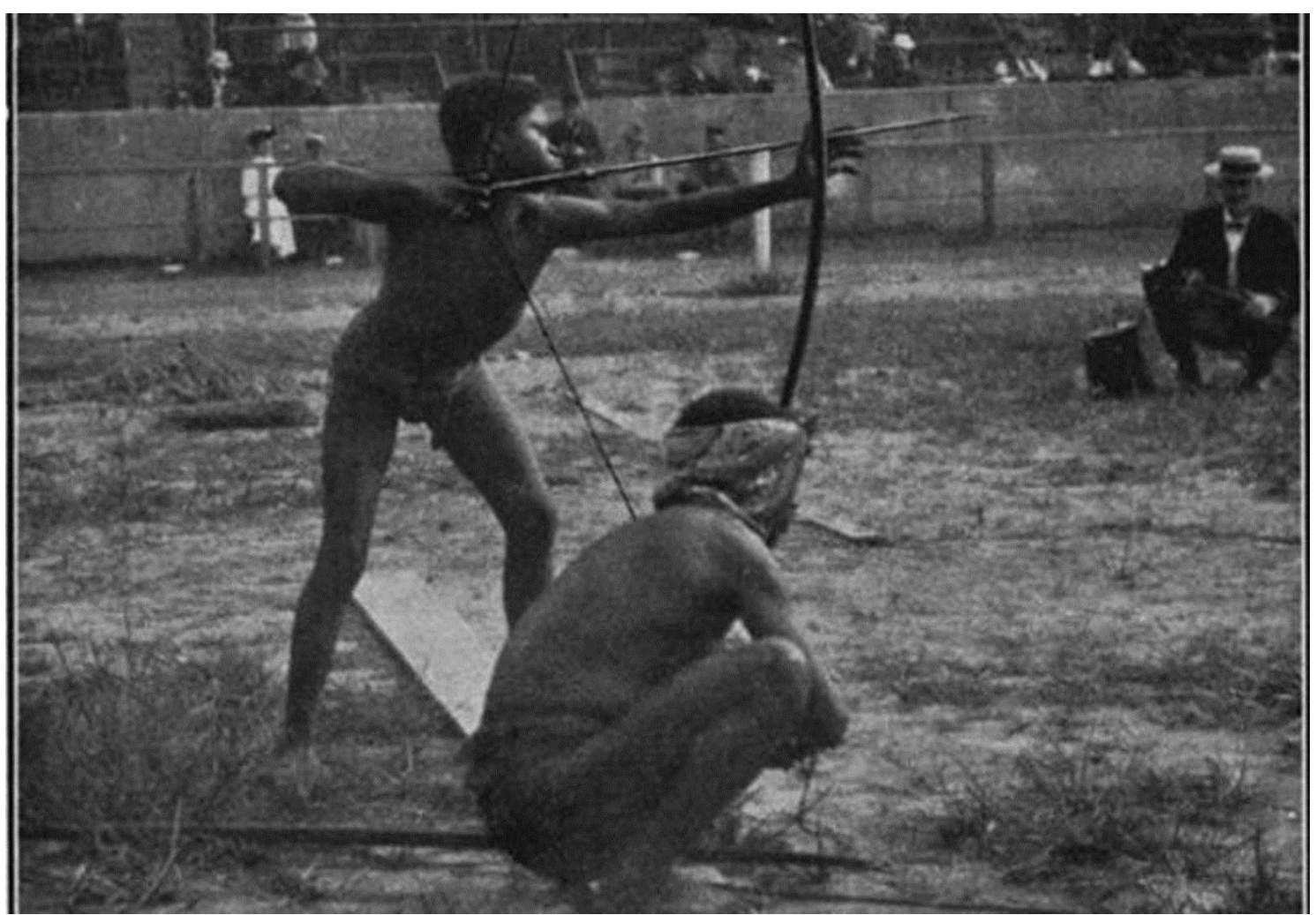

Fuente: Spalding's official athletic almanac (Vol XIII, Número 217, enero 1905)

Otro ejemplo fue la "Pole Climbin Event" o subida al poste de 50 pies de altura. El ganador de la competencia fue el llamado "negrito", perteneciente al grupo de los filipinos. En la imagen se aprecia la destreza del participante con la consiguiente dificultad del poste engrasado y la no existencia de contención ante una eventual caída, cuestión que hacía aún más peligrosa la prueba. Además de la templanza para avanzar en esas circunstancias, se nota el tronco erguido y la mirada puesta en la cima, como queriendo reproducir una práctica que, según la percepción de los organizadores, era normal en este tipo de grupos étnicos. Tal vez con esta prueba se haya buscado establecer un paralelismo con un primate, representación tanto o más despectiva de la que se estaba construyendo y que acentuaba, aún más, esta inferiorización de los otros. 
Imagen 3: Subida al poste o "Pole Climbin Event"

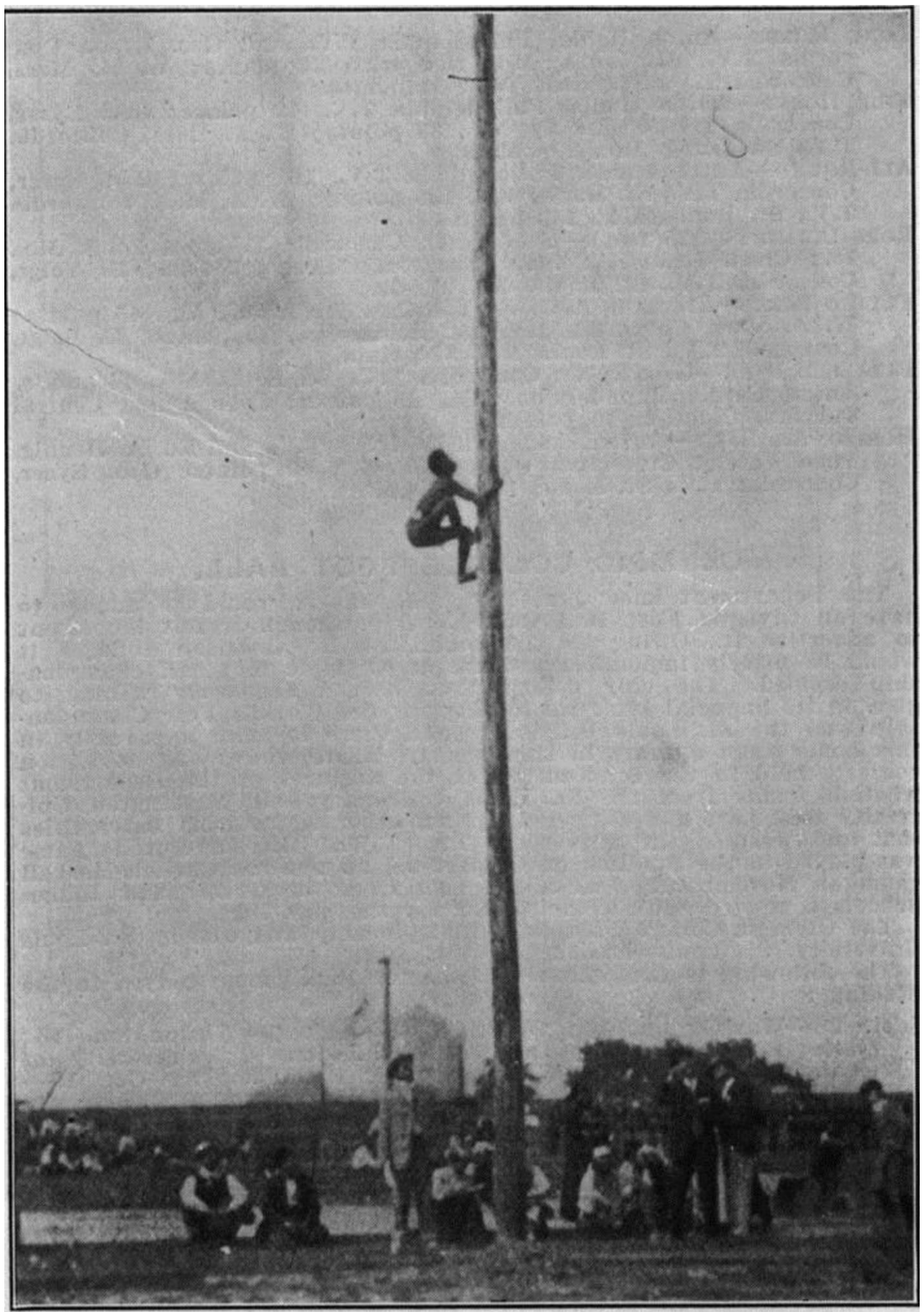

Fuente: Spalding's official athletic almanac (Vol XIII, Número 217, enero 1905)

History of Education in Latin America - HistELA, v. 3, e20788, 2020, p. 8 de 21 
Los otros desafíos fueron pelea en el barro ("pasatiempo favorito de los pigmeos" y comparable, según se señala en la fuente citada, con la guerra de pelotas de nieve de los niños estadounidenses) o el tiro a la cuerda. En este repaso no se puede dejar de mencionar el decoroso papel de los Tehuelches, situación que llevó (según lo planteado por Eduardo Schiaffino, corresponsal de la revista Caras y Caretas) a que "Casimiro y Bonifacio recibieran en Saint Louis proposición de quedarse a razón de cien dólares mensuales contratados por un club atlético" (Caras y Caretas, 15 de julio de 1905).

Estas jornadas sirvieron a diversos propósitos. Para los organizadores (en particular el Estado norteamericano) continuar acentuando en las subjetividades de los espectadores el imaginario dominante de la supuesta superioridad física y moral propia (Mandell, 1986). Si bien Estados Unidos a principios del siglo XX ya era formalmente un Estado-nación, era fundamental seguir recreando ciertos espacios físicos y simbólicos que permitieran consolidar definitivamente el imaginario social de lo "genuinamente americano": blanco, anglosajón y protestante (Bender, 2011). Por el lado de la antropología, en una época de experimentación de estudios antropométricos y psicométricos, permitía contrastar empíricamente las hipótesis de partida acerca de las habilidades motrices "naturales" (diferentes de las que resultan de una educación sistemática), analizadas por prestigiosos especialistas como Woodworth o Bruner, entre otros (Delsahut, 2011).

Con todo, más allá de las posibles interpretaciones, lo cierto es que estas expresiones no eran exclusivas del gobierno norteamericano sino que formaban parte de la retórica legitimadora de las principales potencias occidentales en pos de justificar ideológicamente no sólo la inferiorización del "otro" sino llevar adelante políticas segregacionistas. Hasta los mismos referentes del deporte acordaban al respecto. Por ejemplo, Pierre de Coubertin, si bien es cierto que se opuso insistentemente a la realización de las "Jornadas Antropológicas" (a tal punto de preguntarse de forma irónica en las Memorias Olímpicas publicadas posteriormente (1939) "¿Dirá usted que el mundo no ha avanzado y que la idea deportiva no ha progresado?") consideraba que el deporte moderno podía colaborar en el proceso de civilización de los pueblos colonizados. Al respecto, debemos señalar que la idea del "deporte civilizador" atraviesa toda la obra de Coubertin, desde los discursos o escritos en calidad de funcionario hasta las publicaciones en revistas especializadas.

\section{Palmas, Brasil (2015): Juegos Mundiales de los Pueblos Indígenas}

En el territorio de Brasil conviven en la actualidad una cantidad significativa de grupos étnicos (aproximadamente 300 etnias) que, a pesar del avance del Estado Nacional con el consiguiente proceso de occidentalización y de control territorial, persisten conservando muchos de sus rasgos identitarios (Saléte Grando, 2015). En esto incidieron, entre otras razones, la resistencia al proceso de aculturación a través de la activa participación política (Dávalos, 2005) y el lento avance de la frontera agrícola en algunas zonas. En estas 
últimas décadas los cambios de apreciación respecto de las minorías culturales, generadas por el proceso de globalización (que les da una mayor visibilidad en tanto cuestiona las fronteras nacionales y el imaginario de población homogénea), han llevado a un reconocimiento y aceptación de las diferencias étnicas. Esto se ha manifestado en el campo que nos interesa, por ejemplo, por la promoción de encuentros "intertribales" o en la realización de eventos como los juegos indígenas que se vienen desarrollando localmente desde 1996 y que alcanzaron una expresión internacional desde 2015 (Rubio, De Mello Futada y Da Silva, 2006).

Los Juegos Nacionales Indígenas fueron una iniciativa llevada adelante por el Ministerio de Deportes de Brasil en 1996 retomando una idea original de principios de la década de 1980. A diferencia de las competencias deportivas occidentales, se trata en este caso de "actividades corporales, con características lúdicas, y que en la práctica transmitían los mitos, los valores culturales y por tanto congregaban en sí mismos el mundo material e inmaterial de cada etnia" (Ruiz Vicente y Salinero Martín, 2011). Esta iniciativa surgió de la necesidad de mostrar las costumbres y tradiciones, evitando así cerrarse en sí mismos y recrear la falsa imagen que muchos Estados occidentales habían construido. Tanto éxito tuvieron estas jornadas que se decidió crear (en el marco de la XIII edición celebrada en el año 2013 en Cuiabá) los Juegos Mundiales de los Pueblos Indígenas y así extender la iniciativa a otros grupos étnicos de la región y de otras partes del mundo. El acuerdo surgió del consenso entre el Comité Intertribal Memoria e Ciencia Indígena (ITC), 48 etnias de Brasil y líderes indígenas de otros territorios. Para esta experiencia inaugural, se eligió como anfitrión al Estado de Tocantins por ser una de las regiones con mayor presencia de pueblos originarios (alrededor de trece mil según la página oficial).

¿Quiénes participaron de esta nueva experiencia? ¿Qué requisitos eran necesarios? ¿Cómo se seleccionaron las pruebas? ¿Qué características tenían? ¿Para quienes estaban destinadas? Este primer acontecimiento tuvo una concurrencia de aproximadamente 1800 atletas, de los cuales más de dos tercios pertenecían a grupos étnicos brasileros (entre otros los Kayapó, los Kuikuro, los Wai Wai, los Xavantes) y el resto a países de América (como Colombia, Argentina ${ }^{8}$, Chile, Estados Unidos, Canadá), Africa (Etiopía, por ejemplo) o Asia.

Si bien es cierto que el espíritu y la razón de ser fue la inclusión de colectivos diversos, se establecieron una serie de criterios respecto a la aceptación de los participantes. Así como en el caso de las doce ediciones de los Juegos Nacionales, la condición mínima fue que las etnias hubieran conservado (a pesar de los factores exógenos y las obligadas resignificaciones) su idioma, sus creencias, sus ritos, sus pinturas corporales, su música, sus juegos, en líneas generales, sus costumbres; o según la perspectiva del control cultural propuesta por el antropólogo mexicano Guillermo Bonfil Batalla (1991) los elementos culturales propios (es decir heredados de sus antepasados) y la capacidad de decisión propia sobre los mismos.

El evento se llevó finalmente a cabo entre el 23 y el 31 de octubre de 2015, y en el acto inaugural estuvieron presentes algunas autoridades gubernamentales (entre ellas la presidenta Dilma Rousseff) y líderes de cada una de las etnias. Esta presentación no estuvo exenta de tensiones, se 
visibilizaron protestas, se exigieron respuestas a demandas insatisfechas siendo los funcionarios estatales presentes los destinatarios de los disgustos (Wouters y Van Oorschot, 2016). Pero, a diferencia de los Juegos Antropológicos de Sain Louis, estos pedidos pudieron, por lo menos, ser manifestados. Más allá de esta situación, hubo un gran desfile con bailes, danzas típicas, música autóctona, exhibiciones y degustaciones de comidas típicas que le imprimió el tinte festivo que ameritaba un evento de esta envergadura.

Las pruebas se dividieron entre Juegos de Integración y Juegos de Demostración. Los primeros correspondían a prácticas que la gran mayoría de los grupos étnicos realizaban. Los más tradicionales eran el lanzamiento de lanza (cuyo ganador era quién más lejos llegaba), el arco y flecha (en el que se debía acertar a un blanco) o el cable de fuerza (enfrentamiento entre dos grupos que medían la fuerza y la resistencia). En relación con este último es interesante reparar en la figura siguiente. Por un lado, las protagonistas son las mujeres, que están llevando adelante ejercicios de "fuerza" y "resistencia" tradicionalmente asociado a la imagen sobre lo masculino o la masculinidad (opuesta a la supuesta fragilidad del género y los cuerpos femeninos). Por el otro evidencian gestos de satisfacción, de alegría, del placer que se desprenden del esfuerzo colectivo.

Imagen 4: Enfrentamiento de cable de fuerza

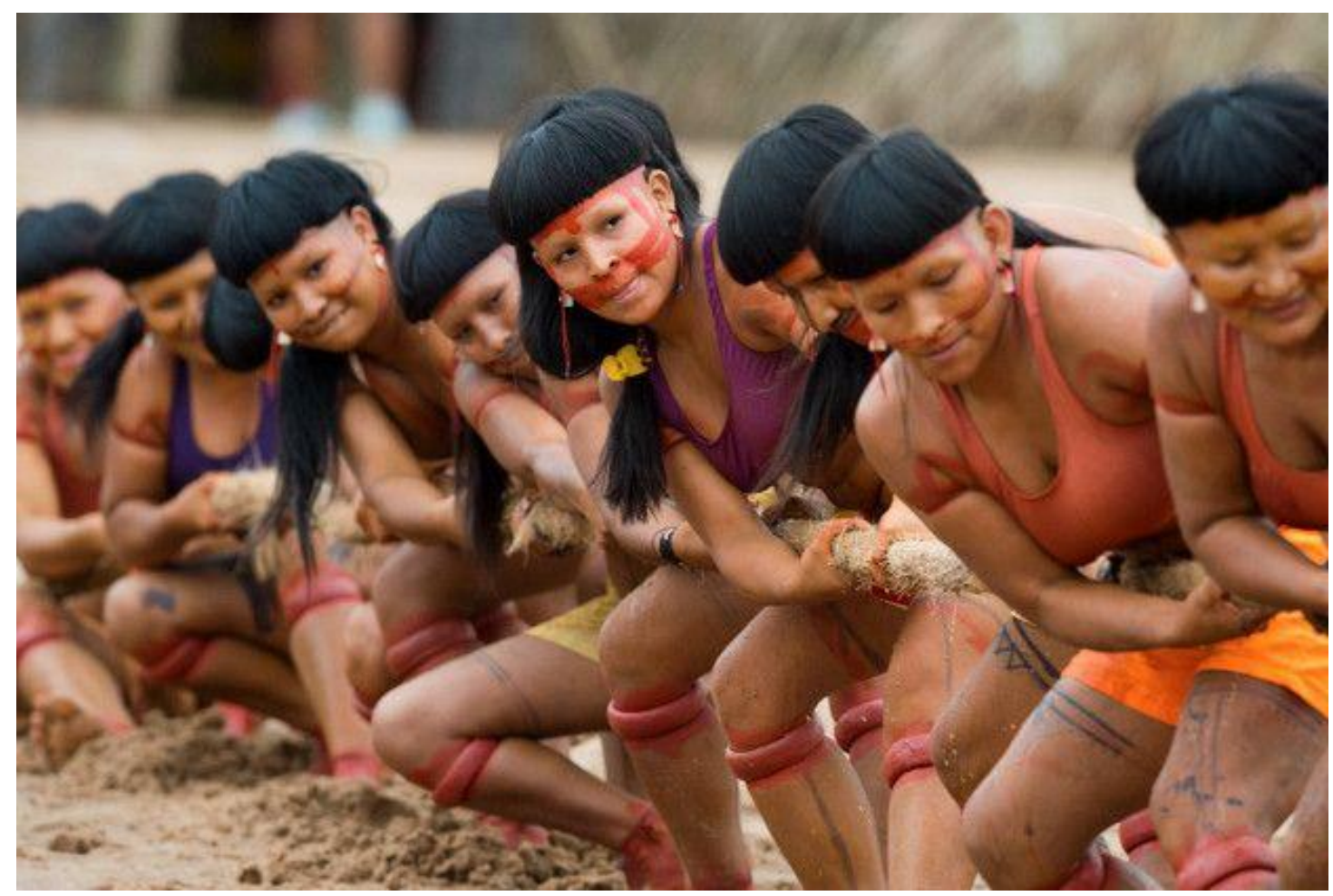

Fuente: Página oficial de los Juegos Mundiales de los Pueblos Indígenas (http://www.jmpi2015.gov.br/).

También se desarrollaron algunas experiencias parecidas a los deportes modernos, pero en muchos casos resignificados. Podemos nombrar, por 
ejemplo, al canotaje (con la diferencia de que las canoas eran de elaboración propia y tenían remos rústicos), natación y fútbol (única disciplina regida por las reglas de la Confederacao Brasileia de Futebol) y las carreras de resistencia y velocidad, con el agregado de que en la llamada "corrida com Tora", como se muestra en la siguiente imagen, se realizaba alrededor de una pista de arena con un peso extra. Se trataba de un tronco de palmera de aproximadamente 120 kilos y, como se observa, la cooperación entre los participantes era fundamental para alentar al que corría con el peso y terminar la prueba.

Imagen 5: Corrida com Tora

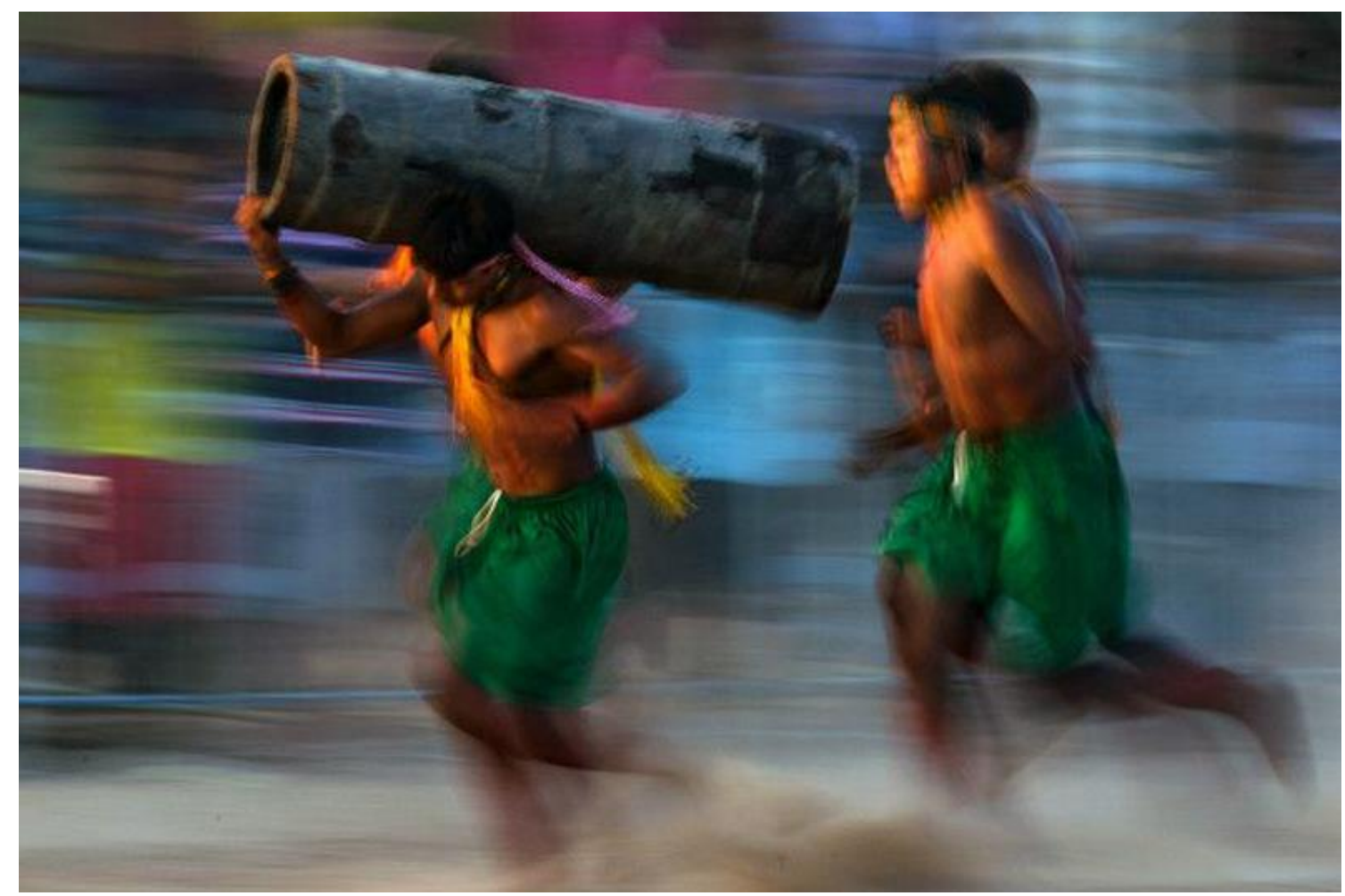

Fuente: Página oficial de los Juegos Mundiales de los Pueblos Indígenas (http://www.jmpi2015.gov.br/).

Los juegos de demostración, por su parte, estaban destinados únicamente a los grupos étnicos locales ya que, a la vez que se construía una identidad amplia "mundial", el Estado brasileño realizaba su recorte nacional. En los mismos se llevaban adelante prácticas específicas generando el conocimiento y visibilización de ciertas costumbres. Encontramos entre ellos el Jikunahati (parecido al fútbol moderno con la diferencia de que sólo se podía usar la cabeza) o el Kagót (una simulación de enfrentamiento en un campo abierto con flechas sin puntas para evitar heridas), entre otros. (Resumo lo anterior con un esquema de elaboración personal con las principales pruebas). 
Cuadro 1: Disciplinas de los Juegos Mundiales de los Pueblos Indígenas

\begin{tabular}{|c|c|c|}
\cline { 2 - 3 } \multicolumn{1}{c|}{} & \multicolumn{2}{c|}{ JUEGOS } \\
\cline { 2 - 3 } & INTEGRACIÓN & DEMOSTRACIÓN \\
\hline \multirow{4}{*}{ INDIVIDUALES } & $\begin{array}{c}\text { Lanzamiento de } \\
\text { lanza } \\
\text { Arco y Flecha } \\
\text { Carrera velocidad } \\
\text { Natación }\end{array}$ & Kaipy \\
\hline \multirow{4}{*}{ GRUPALES } & $\begin{array}{c}\text { Cable de Fuerza } \\
\text { Canotaje } \\
\text { Carrera de Tora } \\
\text { Futbol }\end{array}$ & Jikunahati \\
& Jawari \\
& Cable de Fuerza & Kagot \\
& Ronkrãn \\
& Peikrãn \\
\hline
\end{tabular}

Fuente: Elaboración personal

Como bien se observa en el cuadro, la gran mayoría de las prácticas realizadas en los juegos de demostración eran grupales, lo que implicaba un fuerte sentido de comunión o pertenencia colectiva. A su vez, las disciplinas se dividían por género (incluso algunas eran mixtas). El caso del fútbol femenino es interesante en la medida que no sólo recupera uno de los deportes más populares de Brasil y genera un proceso de mediación intercultural (Saléte Grando, 2015) sino que, al permitir la presencia de mujeres, se abre a la sensibilidad de los nuevos tiempos globales.

Hasta aquí hemos descrito los actores presentes, las características de los juegos y las modalidades de disputa. Si bien se trató de competencias que medían agilidades, destrezas y fuerza, lo cierto es que el exitismo (al que evidentemente nos tienen acostumbrados las olimpiadas modernas y que Eloy Altuve (1997) sintetiza en el siguiente encadenamiento de conceptos: deporterendimiento-récord-campeón-medalla) pasó a un segundo plano. Lo que se valoró en las reseñas fue la confraternización y la cooperación, la reivindicación de las identidades étnicas y el diálogo con el Estado Nacional que, a diferencia de lo observado en las "Jornadas Antropológicas" de Saint Louis en 1904, se mostró abierto a la posibilidad de darle visibilidad a las diferentes expresiones culturales locales, regionales y mundiales. Por otra parte, permitió al público presente y a aquellos que lo siguieron por los medios de comunicación, conocer y experimentar juegos tradicionales que forman parte del patrimonio material e inmaterial de las sociedades. 


\section{Abordaje contrastivo}

Entre las Jornadas Antropológicas y los Juegos Mundiales de los Pueblos Indígenas transcurrieron más de cien años, desde un siglo $\mathrm{XX}$ marcado por discursos racialistas explícitos (Gould, 2013) hasta el nacimiento de un nuevo milenio atravesado por la globalización y el reconocimiento de la diversidad. Si bien las diferencias entre ambos eventos han sido notorias, encontramos, a su vez, algunos ejes (por ejemplo, en lo que respecta a los discursos sociales y las representaciones en torno a los cuerpos) que nos permiten aventurarnos en un ejercicio de comparación en el que se evidencian los sentidos históricos diferentes. Debemos destacar, asimismo, que las diferencias y similitudes que encontramos están a su vez mediadas por el ojo del observador y las matrices ideológicas y discursivas de la época y del sector al que aquel pertenece. En este sentido, hay que considerar que las fuentes que utilizamos para analizar los Juegos Antropològicos pertenecen, fundamentalmente, a órganos oficiales. En cambio, en aquellas consultadas para los Juegos Mundiales de los Pueblos Indígenas aparecen las diferentes voces, tanto de los participantes como de los organizadores.

\section{Discursos, imaginarios, identidades}

Por un lado, ambas competencias proyectan dos formas de visibilidad. Las "jornadas antropológicas", con clara impronta del evolucionismo decimonónico, exponían el supuesto atraso de las etnias participantes frente a la sociedad occidental. El evento del 2015 acentuaba la consideración y respeto de la heterogeneidad de manifestaciones culturales. Esto es entendible si pensamos las ideologías o los discursos en los cuales se inscriben cada uno de estos acontecimientos. El de Saint Louis, dominado por una retórica fuertemente racialista y nacionalista. Los segundos, en un contexto de promoción del multiculturalismo y, por ende, la reivindicación de colectivos hasta entonces silenciados, entre ellos étnicos y sexuales.

En segundo lugar, es incuestionable la diferencia en torno a los responsables de la promoción, desarrollo y difusión de estos dos eventos, resultado de la imagen que se buscaba transmitir. Mientras que en las "jornadas" la decisión corría por cuenta de los propios organizadores (es decir el Estado norteamericano), en el caso de los "Juegos Mundiales" se incorporaba además del gobierno, la sociedad civil y, particularmente, las etnias participantes que concertaban las disciplinas de acuerdo a sus propios gustos y tradiciones. Esto permitió, como mostramos, gestos de disidencia, protestas contra las autoridades que, en el otro contexto hubiese sido imposible.

A su vez, y en consonancia con lo planteado anteriormente, se pueden percibir distancias en las construcciones identitarias de los grupos implicados. En las primeras, se conformaron de acuerdo a un monólogo civilizatorio, en dónde era necesario que el "otro" fuera apartado y cosificado para evitar, así, el inevitable proceso de aculturación propio del contacto con sociedades 
"superiores". Esta jerarquización de las culturas apelaba al aislamiento geográfico como factor crítico para conservar la identidad (Barth, 1976). En el otro extremo, encontramos la representación de "los Juegos mundiales" en donde las relaciones interétnicas se tornan fundamentales para la reafirmación identitaria. Aquí las fronteras que determinan la identificación no son físicas sino límites simbólicos que se reconstruyen en momentos de encuentros interculturales, aunque no sean ajenas a las tensiones con lo global y lo nacional.

En cuarto lugar ( $\mathrm{y}$ de acuerdo a lo manifestado en las fuentes, en particular la crónica realizada por Sullivan) se observa en las Jornadas de Saint Louis una permanente comparación de la performance de los indígenas con las mejores marcas de atletas olímpicos. Este análisis, por cierto, no quedaba reducido a un juicio de hecho sino que estaba siempre acompañado por una valoración despectiva. La ponderación se tornaba entonces, a nuestro entender, necesaria para reafirmar la inferiorización (no sólo intelectual sino física) del otro. Hay que agregar que esta discriminación se ejerció también con los propios participantes, fenómeno que refleja la idea de una diferenciación evolutiva entre los mismos subalternos. En el caso de los Juegos Mundiales, no existe tal planteo o por lo menos no se aprecia en las crónicas consultadas, ya que lo políticamente correcto tiene la fuerza de anular esos posibles desvíos. Se evidenció, en cambio, una valoración de los esfuerzos compartidos y de la participación de la mujer en deportes "tradicionales y modernos".

No podemos dejar de hacer mención al vínculo con los símbolos patrios en cada uno de los acontecimientos. Como señalamos anteriormente, en las Jornadas Antropológicas al ganador de cada competencia se lo premiaba con la bandera estadounidense. Este gesto puede ser interpretado de dos maneras. Por un lado, en virtud del éxito obtenido se les concede la posibilidad de formar parte de la nación. Por otra parte, en la medida que la bandera ocupa un lugar de premio, aparece la valorización del propio Estado. En los Juegos Mundiales, cada grupo étnico posaba espontáneamente con su insignia nacional, lo que demuestra que a pesar de sus reivindicaciones debían exponer el sentido de pertenencia al país que representaban.

\section{Espectáculo, financiamiento y selección de las pruebas}

En el caso de Saint Louis fue el Estado norteamericano quién destinó los fondos para la exposición y las competencias (tanto de las Jornadas Antropológicas como de los Juegos Olímpicos). En el caso de los Juegos Mundiales, si bien el Estado brasileño brindó apoyo logístico, fueron las empresas transnacionales (como el caso de Petrobras) que, para estar a tono con los nuevos tiempos, asignaron presupuesto.

Tal vez en donde más se asemejaron estos eventos fue en la selección de las pruebas. En ambos se diferenciaron los deportes de los juegos autóctonos, recreando, en cierta medida, la falsa dicotomía de deportes modernos y juegos tradicionales que no es ajena al debate historiográfico ${ }^{9}$. No obstante, en el caso de las jornadas de Saint Louis, las competencias fueron íntegramente elegidas por las autoridades mientras que en 2015, fueron los 
propios participantes quienes decidieron finalmente las características de las mismas.

Por último, un contraste evidente fue el papel de los espectadores. En el primer evento, en su mayoría occidentales, el propósito de su presencia era la burla como si se tratara de una exhibición humorística. En el caso de los Juegos Mundiales de los Pueblos Indígenas, no sólo eran multitudinarios sino que se mezclaban indígenas y no indígenas, en dónde estos últimos valorizaban positivamente la experiencia siendo respetuosos de la diversidad (De Jesus Pinheiro Peres, Ferreira dos Santos, Martins Correia y Figueiredo da Silva, 2019).

\section{La representación del cuerpo}

Hablar de cuerpo cultural implica hacer referencia a un universo simbólico polisémico atravesado por lógicas de poder y permeado por contextos (sociales, políticos, económicos, culturales) que legitiman y, en algunos casos, naturalizan su mirada. Pero en toda construcción social (y como sostiene Galak (2016) política) la diferencia radica en quién se apropia del "cuerpo" para consolidar ese discurso. Y esto lo vemos en los dos casos analizados.

La primera diferencia la podemos encontrar en el "contexto" amplio en dónde se encuentra el cuerpo indígena. En el primer caso está ubicado en un ámbito artificial (o por lo menos no familiar), occidental, rodeado de tribunas que muestran la majestuosidad de ese evento a pesar de que en las pruebas se simulaba un entorno "natural". En el segundo caso, el cuerpo está en un hábitat moldeado por los propios participantes en el cual se pretende recrear sus propias condiciones en armonía con el medio-ambiente. No está de más decir que en los juegos antropológicos el espacio es el territorio de Estados Unidos, símbolo desde entonces del imperialismo, la civilización y la opresión de minorías. En el caso de Brasil, territorio diverso en cuanto a su composición étnica, atravesado por historias de tradiciones y la reivindicación del multiculturalismo. En otras palabras, un contexto "impuesto" y un contexto "propio". Y yendo más lejos, en el primer caso, en las imágenes que valora Sullivan, el cuerpo está siempre "solitario", desligado de su propia comunidad, mientras que en el segundo se encuentra generalmente rodeado, enfatizando en la importancia de lo comunitario, lo colectivo.

En segundo lugar, en lo que expresa ese cuerpo por más que, por lo general, se encuentre en una situación análoga: cuasi desnudo. En el primer caso, como describimos, el cuerpo evidencia lo "salvaje", lo cercano a la naturaleza, aquel que no está en condiciones de estar a la altura de la performance del deporte occidental; en última instancia lo cosificado. En los juegos Indígenas manifiesta la tradición, la resistencia, lo genuinamente autóctono. Mientras que en el primer caso se resalta la "negritud" como fenotipo opuesto al "caucásico occidental", en el segundo los cuerpos pintados evocan el orgullo. E hilando más fino, en el primer caso es un cuerpo "capitalista", un cuerpo necesario para el trabajo de fuerza que el pujante avance industrial requiere mientras que en los Juegos Mundiales del 2015 
trata, en apariencia, de un cuerpo emancipado. En otras palabras, un cuerpo dócil opuesto a un cuerpo que resiste, que exige demandas, que es un protagonista político.

Por otra parte, cuando se trabajan sobre materialidades (en este caso el significante "cuerpo") no sólo la presencia genera significados sino también su ausencia. En el caso de "las jornadas antropológicas" la mujer está ausente (por lo menos no hay referencia en las fuentes documentales) lo que genera una doble inferiorización: por parte de la propia comunidad que no la hace partícipe y de los organizadores del evento que no la convocan ni siquiera para estigmatizar al género. En cambio, en los Juegos Olímpicos del 2015, no sólo está presente sino que ocupa un lugar protagónico hasta en deportes, como el futbol, hasta no hace mucho tiempo reservado sólo a los hombres. El caso de los niños es diametralmente opuesto. En el evento olímpico de 1904 la presencia del niño se convierte tanto en metáfora de la instancia evolutiva en la que se encuentran los grupos étnicos (el inicio) como en la actitud paternalista que el hombre occidental debe tener. En cambio, la no presencia en los Juegos Mundiales puede referir a dos etapas bien marcadas dentro de las propias comunidades (la de la niñez y la de la adultez) marcada por un rito de pasaje como es el caso de estas festividades.

Por último, y refiriendo a un contraste más matizado encontramos la diferencia entre la representación del cuerpo y la experiencia atlética. A principios del siglo XX era un hecho que el trabajo sistemático del cuerpo podía conducir al mejoramiento de marcas. Por lo tanto, más allá de la imagen estereotipada y burlona de los indígenas, no se ponía en cuestionamiento su humanidad sino que se los pensaba como seres "incompletos" (Monge, 1999) que, con una educación disciplinada podrían lograr ciertas habilidades llegando, incluso, a emular las marcas olímpicas. Esta confianza en las instancias formativas que la sociedad había establecido, se manifestó no sólo en las pruebas atléticas sino también en los trabajos presentados en la Exposición que mostraban los logros escolares, como se observa en aquellos enviados por los niños de Escuelas Argentinas (y tan bien mostrados por El Monitor de Educación Común, principal órgano de difusión del Ministerio de Educación ${ }^{10}$ ). Por el contrario, en los Juegos Mundiales, al no considerar posible una referencia evolutiva, esa percepción etnocéntrica se encuentra mitigada. A pesar de lo cual, el aspecto disciplinatorio de la experiencia se manifestó en que, si bien se consensuaron las actividades físicas a ser desarrolladas, se establecieron claramente las reglas a las que debían someterse los participantes. Este dispositivo regulador redujo las prácticas a un escenario previamente pautado, como en los juegos olímpicos, lo que no podía dejar de incidir en la subjetividad de los participantes.

\section{Consideraciones finales}

A lo largo de este trabajo recorrimos las características principales de estos dos eventos, considerando el contexto en el cual se inscribieron como así también los actores presentes y las particularidades de cada una de las pruebas. En segunda instancia, realizamos una puesta en común entre ambos 
acontecimientos, reparando en las similitudes y diferencias que se desprendieron del análisis de las fuentes. Esto nos permitió distinguir el contraste de dos imaginarios de época. Uno (el de Saint Louis), el progreso frente al atraso, representación que permitió o legitimó el avance de la frontera agrícola en los Estados Nacionales replegando así a los pueblos indígenas. En cambio, los Juegos Mundiales del 2015 se asentaron en el imaginario de la globalización en el que las diferencias deberían ser resaltadas como forma de erosionar simbólicamente esos mismos Estados mostrando su heterogeneidad constitutiva.

Para concluir consideramos necesario señalar que se trata de una primera aproximación al tratamiento de un fenómeno de significativa importancia como es la reflexión acerca de las prácticas lúdicas y su vínculo con los imaginarios de cada contexto histórico. Resta entonces seguir indagando sobre estos temas que, más allá de estar en algunos casos descuidados por las ciencias sociales, son imprescindibles para dar cuenta de las especificidades de cada sociedad en cada época.

\section{Bibliografía}

Altuve, E. (1997). Juego, historia, deporte y sociedad en América Latina. Maracaibo, Venezuela: Centro Experimental de Estudios Latinoamericanos.

Barth, F. (1976). Los grupos étnicos y sus fronteras. La organización social de las diferencias culturales. México: Fondo de Cultura Económica.

Bender, T. (2011). Historia de los Estados Unidos, una nación entre naciones. Buenos Aires, Argentina: Siglo XXI.

Besnier, N., Brownell, S. y Carter, T. (2018). Antropología del Deporte. Emociones, poder y negocios en el mundo contemporáneo. Buenos Aires, Argentina: Siglo XXI.

Bonfil Batalla, G. (1972). El concepto de indio en América: categoría de situación colonial. Anales de Antropología 9(1) recuperado de http://www.revistas.unam.mx/index.php/antropologia/article/view/23077/pdf_647

Bonfil Batalla, G. (1986). La Teoría del Control Cultural en el estudio de procesos étnicos. Revista de Estudios sobre las Culturas Contemporáneas, 4(12), 165-204. Recuperado

de http://www.dan.unb.br/images/pdf/anuario_antropologico/Separatas1986/anuari 086_batalla.pdf

Burke, P. (2005). Visto y no visto. El uso de la imagen como documento histórico. Madrid, España: Crítica.

Cousineau, P. (2008). La odisea olímpica. Reavivar el verdadero espíritu de los Grandes Juegos. Madrid, España: Ediciones Amara.

Dávalos, P. (2005). Movimientos indígenas en América Latina: el derecho a la palabra. En P. Dávalos (Comp.), Pueblos Indígenas, Estado y Democracia; Buenos Aires, Argentina: CLACSO. Recuperado de http://biblioteca.clacso.edu.ar/clacso/gt/20101026124338/2Davalos.pdf 
De Jesus Pinheiro Peres, J., Ferreira dos Santos, R., Martins Correia, A. y Figueiredo da Silva, C. (2019). Primeiros Jogos Mundiais dos Povos Indígenas: uma análise da percepcao dos espectadores. Motrivivencia 31(59), 01-24. Recuperado https://periodicos.ufsc.br/index.php/motrivivencia/article/view/21758042.2019e57802

Delsahut, F. (2011). Los Juegos antropológicos de Saint-Louis. Revista Brasileira de Ciencias do Esporte,33(4), 809-823. Recuperado de https://www.scielo.br/pdf/rbce/v33n4/a02v33n4.pdf

Delsahut, F. (2012). Los Juegos Olímpicos de San Luis y el nuevo destino deportivo manifiesto de América. Revista Citius 5(2), 71-89. Recuperado de https://dialnet.unirioja.es/servlet/articulo?codigo=4109961

Dunning, E. (2003). El fenómeno deportivo. Estudios sociológicos en torno al deporte, la violencia y la civilización. Barcelona, España: Editorial Paidotribo.

Galak, E. (2016). Educar los cuerpos al servicio de la política. Cultura física, higienismo, raza y eugenesia en Argentina y Brasil. Buenos Aires, Argentina: Ed. Biblos.

García Canclini, N. (2001). Culturas Híbridas. Estrategias para entrar y salir de la modernidad. Buenos Aires, Argentina: Ed. Paidós.

Guttman, A. (2019) [1978]. Del ritual al récord. En P. Scharagrodsky y C. Torres (Ed). El rostro cambiante del deporte. Perspectivas historiográficas angloparlantes (1970-2010) (pp 19-67). Buenos Aires: Editorial Prometeo.

Goud, S. J. (2013). La falsa medida del hombre. Barcelona, España: Editorial Drakontos.

Harris, M. (1985). El desarrollo de la teoría antropológica. Una historia de las teorías de la cultura. México: Siglo XXI.

Hobsbawn, E. (2010). La Era del Capital. Barcelona, España: Editorial Crítica. Jeu, B. (1987). Análisis del deporte. Barcelona, España: Ediciones Bellaterra. Mandell, R. (2011). Historia Cultural del Deporte. Barcelona, España: Ediciones Bellaterra.

Monge, F. (1999). Un largo camino de lágrimas: la política india de los Estados Unidos de América. Revista de Indias LIX(217). Recuperado de http://revistadeindias.revistas.csic.es/index.php/revistadeindias/article/view/836

Park, R. (2018). Fisiólogos, médicos y educadores físicos: biología y ejercicio higiénico y educativo en el siglo XIX. En P. Scharagrodsky y C. Torres (Ed). El rostro cambiante del deporte. Perspectivas historiográficas angloparlantes (1970-2010) (pp 157-207). Buenos Aires: Editorial Prometeo.

Penhos, Marta (2009), "Saint Louis 1904. Argentina en escena" en Di Lisia, María y Andrea Lluch (Editoras) Argentina en exposición. Ferias y exhibiciones durante los siglos XIX y XX, Sevilla, España: Consejo Superior de Investigaciones Científicas.

Rubio, k., De Mello Futada, F. y Da Silva, E. C. (2006). Os jogos indígenas e as contradicoes do confratenizar e competir. Revista Brasileira de Ciencias do 
Esporte, 28(1), 105-119. Recuperado de https://www.redalyc.org/articulo.oa?id=401338527007

Ruiz Vicente, D. y Sallinero Martín, J. J. (2011) Los Juegos de los Pueblos Indígenas de Brasil: la carrera de tora; ATHLOS, 1(s/n). Recuperado de http://oa.upm.es/12307/2/INVE_MEM_2011_111471.pdf

Saléte Grando, B. (2015). Jogo entre'parentes', os procesos de educacao do corpo, esporte e lazer indíegena no Brasil: reflexoes a partir dos jogos dos povos indígenas. Revista do Programa de Pos-graduacao em Educacao da Unochapecó, 17(34) 36-58. Recuperado de https://bell.unochapeco.edu.br/revistas/index.php/pedagogica/article/view/2917

Todorov, T. (2009). Nosotros y los otros; Buenos Aires: Siglo XXI.

Torres, C. (2018). La Educación Física en Estados Unidos (1865-1945). En P. Scharagrodsky (Comp). La invención del "homo gymnasticus". Fragmentos históricos sobre la educación de los cuerpos en movimiento en Occidente (pp.253-279). Buenos Aires, Argentina: Editorial Prometeo.

Vigarello, G. (2001). Corregir el cuerpo. Historia de un poder pedagógico. Buenos Aires, Argentina: Nueva Visión.

Wouters, C. y Van Oorschot, L. (2016). Las observaciones de un gringo. ATHLOS 10(5) 01-10. Recuperado de https://dialnet.unirioja.es/servlet/articulo?codigo $=5593509$

\section{Fuentes consultadas}

Révue Olympique (Número 9, Febrero de 1903).

Revista Caras y Caretas (número 286, 26 de marzo de 1904, página 52; número 354, 15 de julio de 1905, página 53; número 333, 18 de febrero de 1905, página 18).

Cámara de Diputados de la Nación Argentina (Expediente ํํ 15, Archivado oㅜ 14823, Mayo de 1927).

El Monitor de Educación Común (Año 1904; número 5050; pp. 970-972).

Sullivan, J. (Ed.) Spalding's official athletic almanac 1905-1906 (Vol XIII, Número 217, Enero 1905).

Página oficial de los Juegos Mundiales de los Pueblos Indígenas (http://www.jmpi2015.gov.br/).

BBC Mundo, "Los fascinantes deportes que puedes descubrir en los primeros juegos mundiales indígenas" (www.bbc.com/mundo/noticias/2015/10/151023).

Diario digital Globoesporte, "Conheca as 16 modalidades dos Jugos Mundiais dos Povos Indígenas" (http://globoesporte.globo.com/to/noticia/2015/10/conheca-16-modalidadesdos-jogos-mundiais-dos-povos-indigenas.html).

Lucas, Charles (1904), The Olympic Games 1904, St. Louis: Woodward \& Tieran Printing Co. 


\section{Notas}

${ }^{1}$ Siguiendo la observación de Todorov (2009), preferimos utilizar el término "racialismo" para evitar las connotaciones negativas que habitualmente se le asocian al concepto de "racismo".

${ }^{2}$ Para reafirmar esta aseveración basta con reproducir parte de la solicitud a la Cámara de Diputados y Senadores por parte de la comisión organizadora para que amplíe el presupuesto: "La representación argentina en este certamen es, a causa de los escasos recursos asignados, muy modesta en comparación con las notables instalaciones de los demás países y particularmente con las de Brasil y México que han asignado en esta ocasión sumas considerables. Es conveniente que nuestro país muestre dignamente sus fuerzas y progresos y el poder ejecutivo confía en que, con la ampliación de fondos que se solicita (...) podrá compensarse en algo la modestia de nuestra instalación comparada con el brillo presentado por las demás naciones"( Nota enviada el 27 de mayo de 1904 a la Cámara de Diputados y Senadores).

${ }^{3}$ En este sentido eran claras, como sostiene Penhos (2009), las posiciones antagónicas. Aquellos que alentaban la participación argentina -como el senador José Figueroa Alcorta- se basaban en la necesidad de apertura al mundo entablando buenos vínculos con las "naciones civilizadas"; los que se oponían -como el caso de Miguel Cané- consideraban que, al no poder competir en materia de adelantos industriales con Estados más desarrollados, la imagen que se iba a transmitir era de un país atrasado.

${ }^{4}$ La discusión en torno a la ciudad más idónea para albergar este acontecimiento se ve reflejada en la correspondencia entre los organizadores del evento y las autoridades del Comité Olímpico Internacional, publicadas en la Révue Olympique (Febrero de 1903, número 9).

${ }^{5} \mathrm{La}$ traducción me pertenece.

${ }^{6}$ La categoría "Americanized Indian" es prácticamente un oximorum similar a la denominación "indio civilizado". Recordemos que "Indio" es una categoría supraétnica que no reconoce diversidad identitaria alguna sino denota la condición de colonizado (Bonfil Batalla, 1972).

${ }^{7}$ Las dos imágenes que presentamos en el trabajo fueron extraías de la crónica escrita por Sullivan a la que hicimos mención anteriormente.

8 Del territorio argentino participaron los Tehuelches, Huarpes, Diaguitas, Calchaquíes, Ranqueles, entre otros que, a criterio de las autoridades conservaban sus costumbres.

9 El debate historiográfico se divide entre aquellos que, como Guttmann (2019) [1978], sostienen una ruptura entre Deporte Moderno y Juegos tradicionales (acentuando en características como la racionalidad, la búsqueda del récord, entre otros aspectos) y los que, como Jeu (1987) ven una continuidad, acentuando en su aspecto lúdico y ritual.

${ }^{10}$ Según la crónica del Monitor de Educación Común (Año 1904; número 5050; pp. 970-972) fueron enviadas a la muestra, tejidos en paja o seda, proyectos urbanísticos, mapas, trabajos manuales, cuadros fotográficos, entre otros, elaborados por aproximadamente veintidós escuelas de la ciudad de Buenos Aires. 